\title{
Historical perspectives of The American Association for Thoracic Surgery: Lawrence H. Cohn
}

\author{
John S. Ikonomidis, MD, PhD
}

\begin{abstract}
Lawrence Harvey Cohn (Figure 1), 79th president of The American Association for Thoracic Surgery (AATS), was born on March 11, 1937, in San Francisco, California, 1 of 3 children of native San Franciscan parents. At the age of 12 , he was put to work in his father's building materials business, where he came in contact with and learned to respect persons from all walks of life. He attended Lowell High School, the oldest public high school west of the Mississippi, where, in addition to academics, he excelled in basketball and track, being particularly good at the high hurdles. He graduated in 1955.
\end{abstract}

\section{EDUCATION AND SURGICAL TRAINING}

Dr Cohn received his baccalaureate with honors from the University of California, pursuing an atypical curriculum rich in American history, in addition to the usual premedical school courses. In 1958, he entered Stanford University School of Medicine and became a member of Alpha Omega Alpha. He originally was interested in internal medicine, but because of his desire to "really do something for patients," he decided to pursue a career in surgery. At this point, he was to meet Norman E. Shumway (67th AATS president), and the early days that he spent on his service convinced him that he should become a cardiothoracic surgeon. Despite Dr Shumway's nonconformist urgings for him to immediately enter cardiac surgery training, Dr Cohn left Stanford and entered a general surgery residency on the Harvard Surgical Service at the Boston City Hospital. In 1964, he was at the laboratory at the National Institutes of Health for 2 years, working with such greats as Dr Andrew Morrow and Dr Eugene Braunwald, studying myocardial physiology and novel operations for cardiac disease. While there, he also spent 6 months performing cardiac catheterizations in the National Institutes of Health catheterization laboratory. He then returned to California, completing his general surgery training at the University of California,

\footnotetext{
From the Division of Cardiothoracic Surgery, Medical University of South Carolina, Charleston, SC.

Disclosures: Author has nothing to disclose with regard to commercial support.

Received for publication Sept 12, 2011; revisions received July 18, 2014; accepted for publication July 20, 2014; available ahead of print Aug 7, 2014.

Address for reprints: John S. Ikonomidis, MD, PhD, Division of Cardiothoracic Surgery, Medical University of South Carolina, 25 Courtenay Dr, Suite 7030,

Charleston, SC 29425 (E-mail: ikonomij@musc.edu).

J Thorac Cardiovasc Surg 2014;148:1158-61

$0022-5223 / \$ 36.00$

Copyright (c) 2014 by The American Association for Thoracic Surgery

http://dx.doi.org/10.1016/j.jtcvs.2014.07.002
}

San Francisco, before entering the Stanford University cardiothoracic surgery training program in 1969.

\section{SURGICAL CAREER}

Dr Cohn was recruited by Drs John Collins and Francis Moore to join the staff of the Peter Bent Brigham Hospital in 1971. Dr Cohn transformed cardiac surgery at the Brigham Hospital, implementing many of the techniques he had learned at Stanford to dramatically improve the surgical results. He moved up through the academic ranks and was promoted to Professor of Surgery at Harvard Medical School in 1980. In 1986, he succeeded Dr Collins as the Chair of Cardiac Surgery and in 2000 was awarded the Virginia and James Hubbard Chair in Cardiac Surgery, the first endowed Chair in Cardiac Surgery at Harvard Medical School. Dr Cohn was awarded an honorary Masters of Medicine from Harvard in 1989 and a Doctor Honoris Causa from the University of Paris in 1992. In 2005, he was the recipient of the Paul Dudley White Award, the highest award given by the American Heart Association. Dr Cohn has performed more than 11,000 cardiac surgical operations and is a world-renowned expert in the field of valve repair and replacement surgery and minimally invasive heart valve surgery.

\section{CURRICULUM VITAE HIGHLIGHTS}

Dr Cohn has published more than 470 original scientific articles, 105 book chapters, and 12 books, including editing the second, third, and fourth editions of Cardiac Surgery in the Adult, the most referenced text book in adult cardiac surgery today. He has given more than 750 lectures worldwide. Dr Cohn has had many nonmedical consulting activities. He has been a board member of the Boston Public Library Foundation, an active member of the Museum of Fine Arts, and a Trustee of Massachusetts Financial Services, a mutual fund company. Dr Cohn's clinical and research interest span the entirety of adult cardiac surgery, including reconstructive valve surgery and minimally invasive technology. At the National Institutes of Health, he published work on mitral stenosis, ${ }^{1}$ aortic stenosis, ${ }^{2}$ atrial septal defects, ${ }^{3,4}$ hypertrophic obstructive cardiomyopathy, ${ }^{4}$ and cardiac metabolism. ${ }^{5} \mathrm{He}$ also directed the Cardiac Surgery Laboratory at the Brigham and Harvard Medical School from 1971 to 2001, with an extensive publication history in myocardial protection, coronary artery disease, valve surgery, valve prostheses, and cardiac transplantation. 

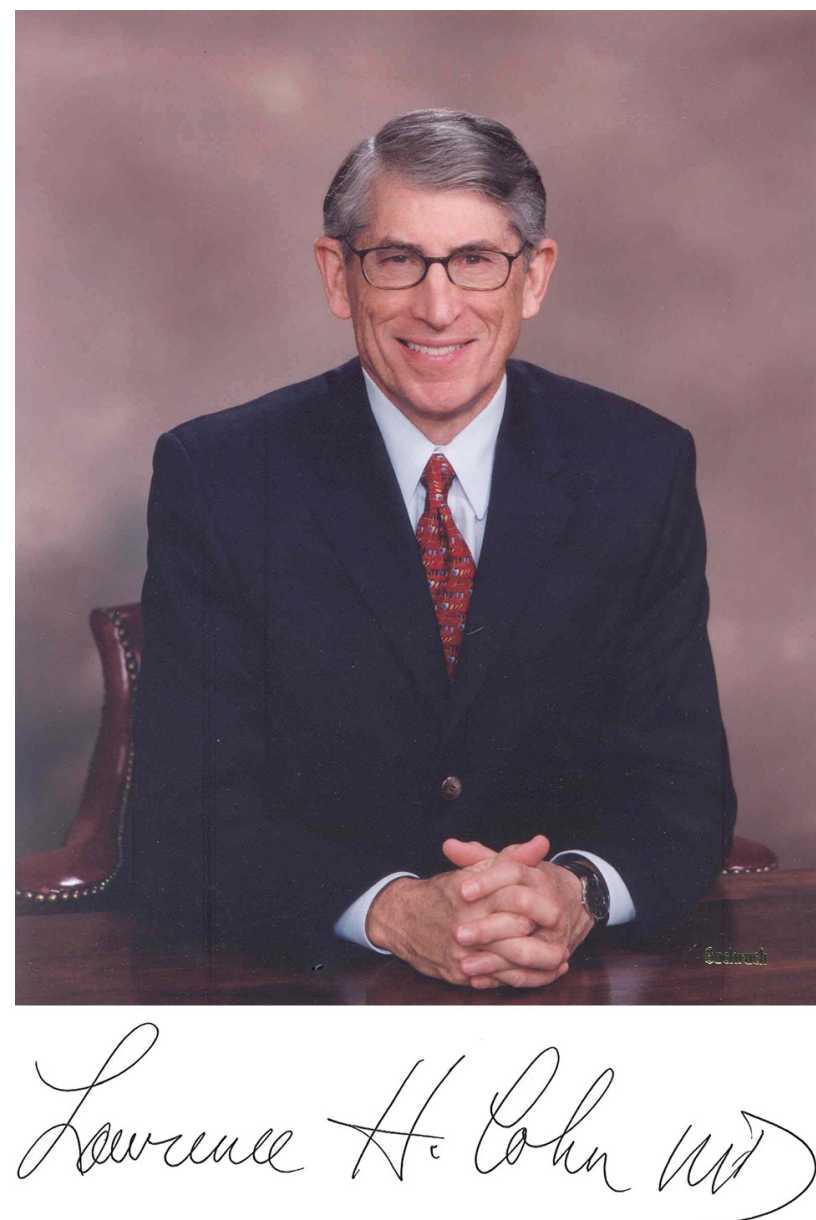

FIGURE 1. Lawrence H. Cohn, MD.

\section{SUMMARY OF AATS PRESIDENTIAL ADDRESS}

In his 1999 Presidential Address titled "What the Cardiothoracic Surgeon of the Twenty-First Century Ought to $\mathrm{Be},{ }^{\circ} \mathrm{Dr}$ Cohn ushered in the new millennium with a list of 11 qualities that the ideal cardiothoracic surgeon should have (Table 1). Of these qualities, which include expertise

TABLE 1. What the cardiothoracic surgeon of the twenty-first century ought to be

\section{Be an excellent surgeon}

Be a physiologist

Be an excellent teacher

Be very knowledgeable about the economics of health care

Be well versed in digital technology

Be knowledgeable, if not expert, about advances in new surgical

technology

Be a leader

Be adaptable

Be persistent

Have a good sense of the history of our specialty

Above all, be a humanist

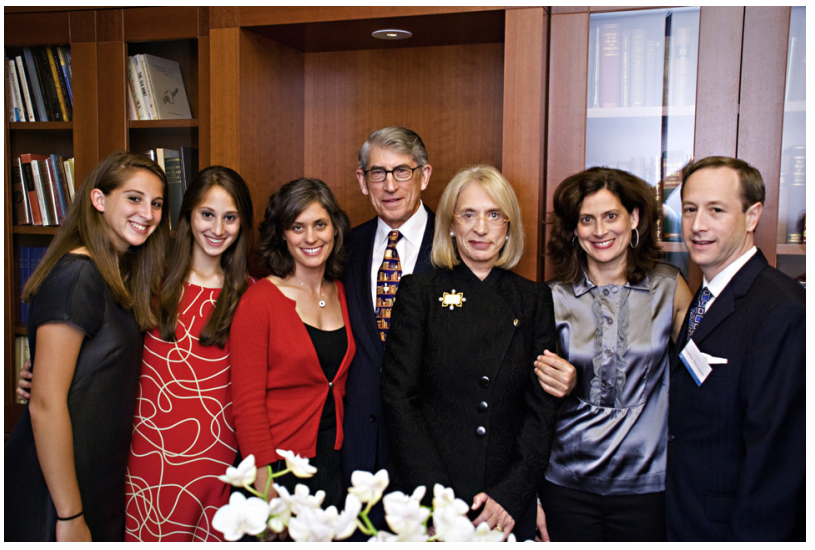

FIGURE 2. Dr Cohn and his family. Left to right: granddaughters, Carly and Rachel Bernstein, daughter Jennifer Cohn, Dr Cohn, Mrs Roberta Cohn, daughter Leslie Cohn Bernstein, and son-in-law Stephen Bernstein.

in surgical technique, education, physiology, healthcare economics, and leadership, Dr Cohn considered the quality of persistence to be perhaps the most valuable for professional and personal success ${ }^{6}$ :

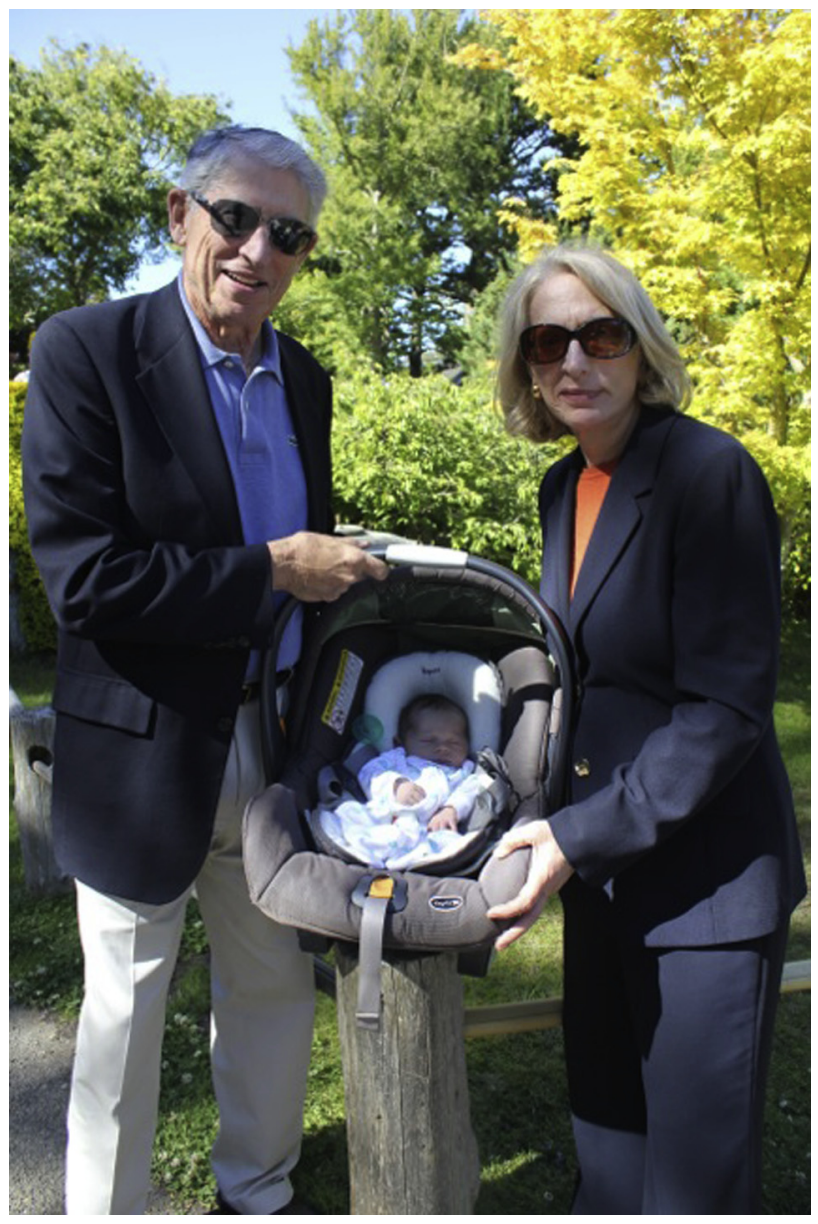

FIGURE 3. Dr and Mrs Cohn with their latest grandchild, Cameron, born June 2014. 


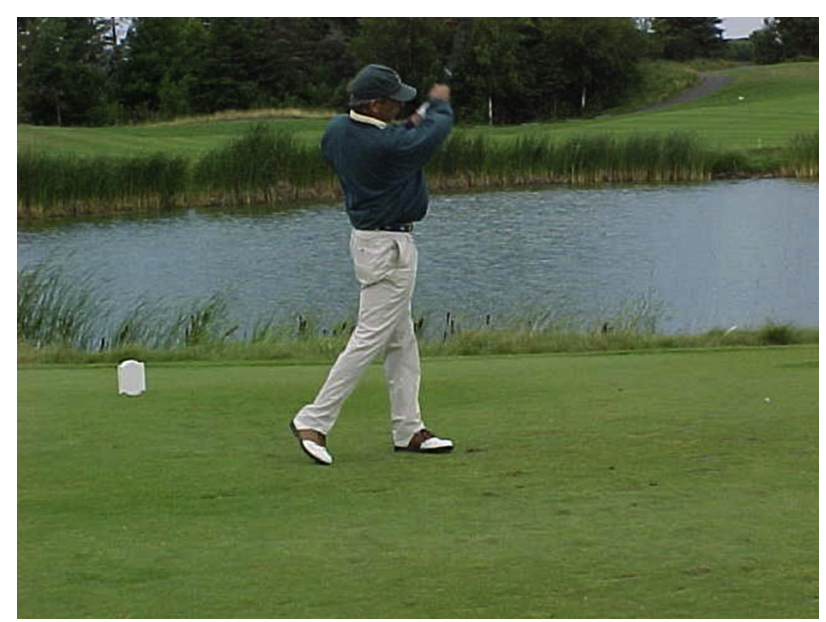

FIGURE 4. Dr Cohn enjoying some time playing the annual golf tournament, which bears his name, the "Larry Cohn Invitational."

Persistence is perhaps the most important personal quality in any successful cardiothoracic surgeon. It is a quality we need in clinical and laboratory research, ... for negotiations with managed care, and ... learning the "ins and outs" of Washington beltway interactions.

\section{ACCOMPLISHMENTS AND CONTRIBUTIONS TO THE FIELD OF CARDIOTHORACIC SURGERY}

Dr Cohn has held office in the American Board of Thoracic Surgery and the American College of Cardiology. He has also been the President of the American College of Chest Physicians and Chairman of the Board of the National Library of Medicine in Bethesda. Dr Cohn was the eighth editor of the Journal of Thoracic and Cardiovascular Surgery from 2008 to 2014, the world's oldest and most authoritative journal in the field of thoracic surgery. During his tenure as editor, Dr Cohn introduced several new sections, including education and training and expert commentary, reintroduced the Presidential Perspectives to be completed in time for the AATS Centennial in 2017, and prioritized the service-line concept to promulgate our specialty and help us extend the best possible care to our patients, which he notes is "the most important objective" and "the very reason for our Journal's existence." ${ }^{, 7} \mathrm{He}$ also edited, for the first time, 1 issue (September 2014) dedicated solely to studies presented at The AATS Annual Meeting.

Dr Cohn has trained more than 150 residents and fellows at Brigham and Women's Hospital/Children's Hospital Medical Center Cardiothoracic Residency Program. Graduates of this program occupy responsible positions at major medical centers worldwide, including approximately 30 surgeons who are division chiefs or department chairs. For many years, Dr Cohn has been a collector of rare cardiology and cardiac surgery books. In 2008, he donated his entire collection to the Lawrence H. Cohn Library created in his name as part of the Carl J. and Ruth Shapiro Cardiovascular Center at the Brigham and Women's Hospital.

\section{PERSONAL LIFE}

Dr Cohn met his wife, Roberta, a University of California, Berkeley, graduate, in high school, and they have been married for more than 50 years. Roberta is an overseer at the Museum of Fine Arts and is a major fundraiser for several nonprofit organizations in Boston. The Cohns have 2 daughters, Leslie Bernstein (a science teacher and school principal of Winsor School for Girls in Boston) and Jennifer Cohn (who works as an environmental consultant in San Francisco). The Cohn's with their 2 daughters, son-in-law Stephen Bernstein, and 2 granddaughters, Carly and Rachel are shown in Figure 2. Dr Cohn became a grandfather for the third time with the birth of his grandson Cameron in June 2014 (Figure 3). The Cohns currently reside in Chestnut Hill, Massachusetts. Dr Cohn enjoys history, tennis, golf (Figure 4), skiing, fishing, sailing, and reading.

Dr Cohn learned "how important a supportive family is to a recovering surgical patient" when he underwent minimally invasive aortic valve replacement in the late 1990s, an experience he believes made him a better physician. ${ }^{6} \mathrm{He}$ also came to appreciate the importance of the patient-doctor relationship, but from the other side of the stethoscope ${ }^{6}$ :

One of the most important times of each day was when my surgeon came in late at night to make his rounds, shake my hand, and discuss my progress. There was an uplifting of spirits that made me feel better in every way. ... It is important, if only for a brief social visit, to touch each patient, to give him or her confidence, and describe how things are progressing and why.

Dr Cohn used his personal experience as a patient to conclude his AATS presidential address by reminding us that "the cardiothoracic surgeon of the 21 st century, above all, ought to be a humanist." Dr Cohn has led by example throughout his career as the consummate technician, prolific investigator, innovative leaders, and dedicated teacher, representing the perfect example of what the cardiothoracic surgeon of the 21 st century ought to be.

\section{References}

1. Cohn LH, Mason DT. Determinants of the height of the left atrial contraction wave in mitral stenosis. Am J Cardiol. 1966;18:724-8.

2. Cohn LH, Mason DT, Ross J Jr, Morrow AG, Braunwald E. Preoperative assessment of aortic regurgitation in patients with mitral valve disease. Am J Cardiol. 1967;19:177-82.

3. Cohn LH, Morrow AG, Braunwald E. Operative treatment of atrial septal defect: clinical and haemodynamic assessments in 175 patients. Br Heart J. 1967;29:725-34.

4. Mason DT, Cohn LH, Ross J Jr, Braunwald E. Idiopathic hypertrophic subaortic stenosis: effects of changes in heart rate on the severity of obstruction to left ventricular outflow. Am J Cardiol. 1967;19:797-805. 
5. Reis RL, Cohn LH, Morrow AG. Effects of induced ventricular fibrillation on ventricular performance and cardiac metabolism. Circulation. 1967;35: I234-43.

6. Cohn LH. What the cardiothoracic surgeon of the twenty-first century ought to be. J Thorac Cardiovasc Surg. 1999;118:581-7.
7. Cohn LH. What is changing and what isn't in the Journal of Thoracic and Cardiovascular Surgery: the cardiovascular and thoracic service-line concept. J Thorac Cardiovasc Surg. 2008;135:1-2.

8. Cohn LH. Update on the cardiovascular and thoracic service-line concept J Thorac Cardiovasc Surg. 2008;136:1403. 